\title{
Assurance OF QUALITY AND THE ACCESSIBILITY of Public Spaces under CurRent Legislation
}

\author{
Alzbeta BILKOVA ${ }^{1}$, Petra KOCUROVA ${ }^{2}$, Renata ZDARILOVA ${ }^{3}$ \\ ${ }^{1}$ Department of Urban Engineering, Faculty of Civil Engineering, VSB - Technical University of Ostrava \\ Ludvika Podeste 1875/17, 70833 Ostrava - Poruba, Czech Republic \\ ${ }^{2}$ Department of Urban Engineering, Faculty of Civil Engineering, VSB - Technical University of Ostrava \\ Ludvika Podeste 1875/17, 70833 Ostrava - Poruba, Czech Republic \\ ${ }^{3}$ Department of Urban Engineering, Faculty of Civil Engineering, VSB - Technical University of Ostrava \\ Ludvika Podeste 1875/17, 70833 Ostrava - Poruba, Czech Republic
}

alzbeta.bilkova@vsb.cz, petra.kocurova@vsb.cz,renata.zdarilova@vsb.cz

DOI: $10.31490 /$ tces-2018-0006

\begin{abstract}
This paper focuses on the issue of accessibility and the quality of public space, particularly its barrier - free use and relation to current Czech legislation. The legislative framework should help reshape theoretical knowledge and contemplations of this issue into live practice, which is met with varying success. Important factors in this field include the continuity of the legislative environment and specifics for the given region (primarily in the border regions where there is a collision of the "domestic" and "foreign" legal environments).
\end{abstract}

\section{Keywords}

Accessibility, barrier - free, Czech legislation, public area, quality, visual use.

\section{Introduction}

The issue of the quality and accessibility of public spaces today is a globally discussed topic. In many (mainly European) cities they are transformed and revitalized. Often these changes omit the importance of the coherence and complexity of the solution which is often focused only on aesthetic impression; whereas the overall quality of public spaces is what people really perceive the most when using them. A frequent insufficiency accompanying barrier - free modifications is the absence of continuity and relations to the broader surroundings and routes. This is where disputable areas arise, where even through successful modifications (conforming to normative parameters) the main objec- tives of an accessible barrier - free environment are not fulfilled - mainly comprehensibility and safety. Therefore, it is necessary to continuously reflect and monitor the efficiency and impact of all normative and legislative requirements on the real environment and operation. Globally the mobility of all inhabitants, without differences, is encouraged, for example "International Walk Charter" ("Walk21, which is a civil and social organization supporting and promoting walking, founded by Jim Walker of Great Britain."). This charter contains several clauses of which the first two are important for the issue of accessibility: Increased mobility for all and Smartly designed and maintained public spaces. These clauses define the rights and demands of people for accessibility and the use of buildings, streets, squares and transport, regardless of their age, physical or mental abilities, gender, language, culture or religion; all this in a healthy and pleasant environment which corresponds to their needs.

\section{BARRIER-FREE (ACCESSIBILITY) ENVIRONMENTS IN THE CZECH REPUBLIC}

There are about 500 million handicapped people living in the world (i.e. about every tenth person). More than one third of persons aged over 75 years suffer from certain handicaps which limit them substantially in certain daily activities. According to data from the Czech Statistical Office, in 2007 in the Czech Republic alone there lived about 1.015.548 persons with hand- 
icaps (The accuracy of these calculations is, however, disputable because there is not currently a national registration of these persons.) [7] Over the last twenty five years the Czech Republic has systematically and intentionally accepted increased responsibility for the elimination of barriers which prevent persons with limited mobility or orientation from leading a full life. The country is striving to provide for all areas which affect these people in order to achieve better conditions and quality of their lives. This is supported primarily by the National Plan whose main aim is to implement and support integration of these people. Regulation No. 398/2009 Coll., on the general technical requirements for ensuring the barrier - free use of buildings, which focuses on this issue in detail for indoor and outdoor environments, has become a key document in the Czech legislative environment.

\section{PUBLIC AREA}

Public areas (or open space) form an integral part of urbanized land. In the Czech legal environment it is defined by Municipalities Act No. 128/2000 Coll., in Section 34: "Public areas are all squares, streets, marketplaces, pavements, public greenery, parks and other areas accessible to all without limitations, i.e. serving the public use regardless of the ownership of such areas." A public area also forms the systemic skeleton of the physical structure of an urban flat town, which is based on the quality of development. Through it we perceive the town, become familiar with the cultural heritage of the town, the character of its society and individual persons; that is what makes up a town. Public areas are the face of a town - they communicate, represent and procure the internal life outwards. [6]

The current status of public areas often suffers from insufficiencies in the form of the unused potential of the town, a missing concept of development of abundant public open spaces, the lack of their interconnection, insufficient maintenance, low aesthetic value, heavy burdening by automobile traffic and mainly numerous social, mental and physical barriers [6]. In our environment these areas were often established mainly during the post - war years (1950s - 1980s) during the building of modern towns abundant with (prefabricated) housing developments with tower and prefab type large scale buildings.

\subsection{Quality of Public Areas}

One of the most renowned representatives involved in the quality of public areas is the Danish architect Jan Gehl; whereas in the Czech environment one can draw complex information especially from the Manual for

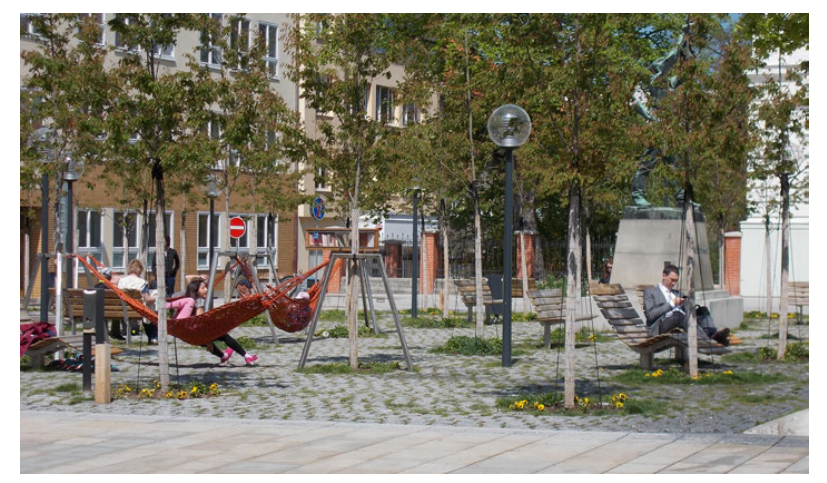

Fig. 1: TG Masaryk Square in Tabor - An Example of a Functioning Public Space (author: Alzbeta Bilkova, 2016).

Creation of Public Areas of the Capital Prague (by Pavla Medkova and the team), which was drafted as a basis for solving access to public areas in our capital city. The quality of public areas is a key parameter for its users; otherwise it loses its attractiveness. This quality defines the degree of spending time in the town's exterior and time spent outside a private space. This time then forms the town life and the town itself. [5] A public area, if well designed, contains certain areas which provide for the required quality. It is primarily a question of ensuring aesthetics and accessibility. Accessibility - means a comfortable and independent access, entry, exit or use of a building, its services and equipment by all potential users (regardless of their handicap, age or gender) - including the provision for health, safety and good living conditions during these activities. In the Czech environment, this term is used primarily to describe the issues of public areas and in the theory of urbanists or architects. In the legislative environment it is substituted by the term barrier - free. However, in practice this has caused misunderstandings in the form of the simplification of this issue or the misunderstanding of their need. The "aesthetics" of a public area contains mainly the necessary, user - friendly and comprehensible furniture, such as benches, waste bins, toilets, stands, etc. Further, natural and water elements in the form of trees, grassed areas, flowerbeds, fountains, drinking taps or other equipment. The "accessibility" of a public area is based on several partial terms, whose interconnection then achieves full and valuable accessibility. The first is the accessibility of areas provided for by systematically designed pedestrian and cycle routes and urban and individual transport, accessible comfortably mainly for pedestrians. Routes to them must be direct without any unnecessary bypasses or other barriers. Obstacles to prams, children, senior citizens and handicapped persons are also considered barriers. Another term is the comprehensibility of the environment, providing for using information and orientation with height or spatial breakdown or orientation points. The last term is safety of the area, in terms of operating and 


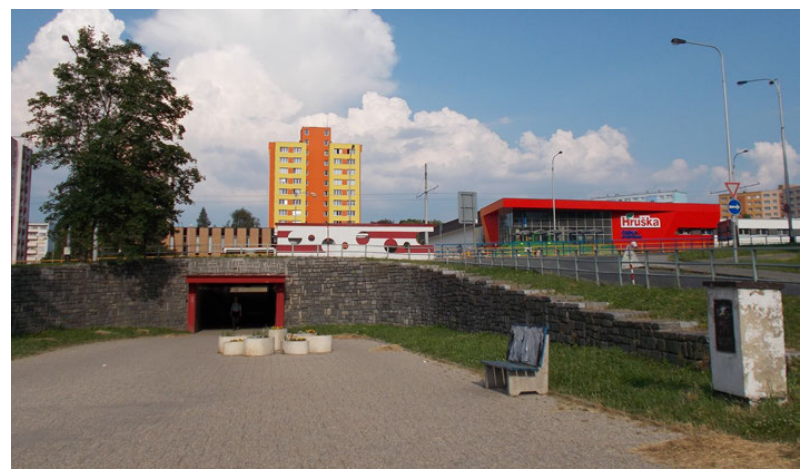

Fig. 2: Ostrava - Vyskovice - an example of the concept of the public space of a housing estate without greater ambition to support and make a pleasant stay in this area (author: Alzbeta Bilkova, 2015).

traffic, as well as the feeling of safety (providing for social/control) and consideration (addressed together with consideration of the needs of persons with limited mobility or orientation).

\section{1) Barrier - Free (Accessibility) and Public Areas}

It is necessary to ensure that the barrier - free use of outdoor areas is designed including access to public buildings and structures also for all persons with limited mobility and orientation, and thereby prevents their exclusion from activities occurring in public areas. The interconnection of the outdoor and indoor environments should be such so as to prevent the creation of other barriers due to unsuitable design and connection and rather to enhance its quality. The integration all these requirements is a hard nut to crack especially in the case of the accessibility of current and historical towns and municipalities. However, design problems are not excluded even in newly made areas, where errors in barrier - freeness are often based on a misunderstanding of the legal and normative regulations or their mechanical solution.

To ensure barrier - free it is necessary to not only observe valid regulations but mainly the general criteria determining and defining independent barrier free, if necessary. With respect to barrier - free use, such areas have 7 properties, namely:

1. Safety (mainly in the form of the elimination of the risk of criminal activities; elimination of areas without social control; limitation of excessive quantities of greenery, etc.);

2. Comprehensibility (ability of orientation of all persons without the help of others; inclusion of memorable orientation points; clear marking and pictograms; intuitive layering of spaces, etc.);
3. Availability (limitation of barriers preventing access by all persons without difference; walking distances; time and property-legal limitations);

4. Usability (from design to implementation of the whole area and respective elements; integration into the town footprint and its spatial - social relations);

5. Pleasure (pleasure from the environment; attractiveness or representation; experience; possible relaxation, sports, cognition, culture, games and meeting);

6. Consideration (mainly the opportunity for unlimited use by all persons without difference; conformity with the environment, etc.);

7. Functionality (mainly in relation to the respective parts of elements). Terms defining the quality of public areas (see chapter above) correspond to the first three properties of barrier - free environments (availability, comprehensibility and safety). From there one can derive that if a public area is considered "quality", it is also barrier - free to a large extent.

\section{CZECH REPUBLIC LEGAL ENVIRONMENT}

The issue of barrier - removal from public areas in relation to the development of the Czech Republic legislative environment is one of many problems which today's municipal council members and designers face during the renewal and building of public spaces in municipalities and towns. Substantial changes in the legislation are often visible in the architecture, performance of modifications and additional building of public spaces. It often happens that new follows into old and a complex approach to the solution is missing, which is extremely important for the correct realization of barrier - free modifications. Without maintaining continuity, barrier-free modifications, although performed correctly and conforming to legislation, become ineffective and therefore unsuitable for use by persons with limited mobility and orientation abilities. [2] The legal environment of the Czech Republic has been approaching the barrier - free question systematically for over sixteen years. In 2001 the first bylaw in the form of Regulation No. 369/2001 Coll., on general technical requirements ensuring use of buildings by persons with limited mobility and orientation abilities was issued, in which definitions of the basic terms, scope of application, technical parameters and dimensions for securing barrier - free use of the outdoor environment and buildings, were included. This regulation was supplemented in 2006 and amended to Regulation No. 492/2006 Coll. 
Another, and final for the meantime, modification of the regulation aimed at barrier - free issues was made in 2009, when a substantial change in the content was made and a new complete Regulation No. 398/2009 Coll., about general technical requirements ensuring the barrier - free use of buildings (hereinafter Regulation No. 398/2009 Coll.), was issued, which is valid to this day [1]. These above said regulations are complemented with Czech and European standards which contain graphic diagrams and descriptions of barrierfree modifications and solutions. These include primarily CSN ISO 21542 Building construction - Accessibility and usability of the built environment (hereinafter "CSN ISO 21542"), CSN 734108 Sanitary facilities and changing rooms, CSN 734130 Stairways and sliding ramps - Basic requirements, CSN 736056 Parking areas for road vehicles, CSN 736110 Design of urban roads, and CSN 73 6425-1(2) Bus, trolley bus and tramway lines halts.

\section{ENSURING BARRIER-FREE CONDITIONS IN THE CZECH ENVIRONMENT}

As was mentioned above, Czech legislation has focused on the issue of creating an environment without barriers systematically and over a long time. In this chapter we shall take a closer look and the structure, requirements and insufficiencies of two of the most important (already mentioned regulations), i.e.: Regulation No. 398/2009 Coll. and CSN ISO 21542.

\section{1) Regulation No. 398/2009 Coll., about General Technical Requirements Ensuring Barrier - Free Use of Buildings}

This regulation defines the general technical requirements for buildings and their parts so as to ensure their use by persons with mobility, sight, hearing and mental handicaps, elderly persons, pregnant women, persons accompanying children in prams or children up to three years of age. For these persons the users use a collective term - persons with limited mobility or orientation abilities. Accordingly, it conditions the whole structure of the document, whose individual appendices are always divided into requirements for general public, users with limited mobility and users with limited orientation abilities [4]. Appendix No. 1 focuses on general technical requirements ensuring the barrier - free use of buildings, particularly the basic elements of the barrier-free use of buildings, staircases and levelling steps, lifts, lifting platforms, moving stairs and pavements, for which it defines minimal dimensions, handling areas, inclines and location. Appendix No. 2 focuses in detail on the technical requirements for ensuring the barrier - free use of roads and public areas. It defines the needs of roads for pedestrians and the number of reserved parking spaces, elements, dimensions, inclines, colours and the location of pedestrian crossings, points for crossing, public transport stops, etc. The individual types of artificial guide lines are defined in detail. Appendix No. 3 focuses mainly on the internal environment of buildings (civil equipment, building equipment of residential buildings, a modifiable apartment or an apartment for special purposes and buildings for work) and defines the minimal dimensions, handling areas, inclines, the design and location of barrier - free entrances to the building, ramps, doors, windows, hygienic facilities and dressing rooms (toilets, re - dressing cubicles, baths, showers and boxes), apartment homes with apartments for special purposes or modifiable apartments. Appendix No. 4, the final appendix, defines five symbols for equipment or spaces, according to the type of limitation (for persons with wheelchairs, persons with impaired vision, persons with impaired hearing, persons accompanying children in prams or a symbol of a space with a re dressing table). One of the most significant insufficiencies of this regulation is a very simplified approach to the deaf and persons with impaired hearing by using an induction loop. Not enough room is focused on the use of Braille lettering and the definition of colour contrasts of guiding and warning elements, and surfaces are described quite generally. Further, no emphasis is placed on the need to perform all modifications and routing of barrier - free routes subject to concurrence and continuity with the environment. The issue of information systems, definitions and modifications of names and signs is missing altogether (contrasts, visibility, location and materials).

\subsection{CSN ISO 21542 Building Construction - Accessibility and Usability of the Built Environment}

This international standard provides the requirements and recommendations for the creation of a sustainable environment in buildings, which is accessible to all persons. It defines how it should be repaired, designed and built, with an emphasis on the actual access, entrance, use and exit from buildings by all persons without any differences, similarly to Regulation No. 398/2009 Coll. Overall it contains 42 sections which focus on the respective issues of ensuring a barrier - free external and internal environment or its equipment. Furthermore, it is complemented by five informative appendices defining mainly tactile elements of treading areas, human abilities and related issues in terms of design, handling 


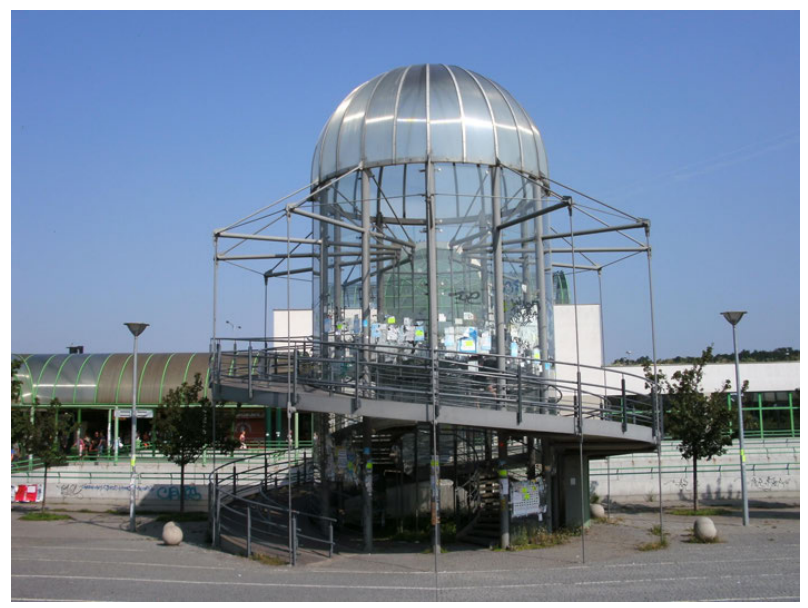

Fig. 3: An example of an inadequately designed ramp that does not allow separate barrier-free use (slope and shape) Prague - Cerny Most (author: Alzbeta Bilkova, 2013).

areas at doors and fire safety and assisted evacuation of all persons. [3] Similarly, Regulation No. 398/2009 Coll. defines for whom the modifications are intended. These are then divided into persons with hearing, eyesight, mobility or mental handicaps, persons with latent insufficiencies (strength, stamina, skill and allergies) and persons with differences according to age and stature (seniors, children, women, etc.). By its requirements for ensuring barrier - free use, it supplements Regulation No. 398/2009 Coll. mainly in the area of visual contrasts, colours and patterns, orientation and the provision of information, signs and symbols, lighting, acoustic environment, floors and walls. Contrary to Regulation No. 398/2009 Coll. it clearly defines values of the reflectivity of light pursuant to a LRV points scale with determination of necessary visual contrasts for various surfaces in the environment. The methods and calculations for determining visual contrasts are specified in information appendix B.7 - Visual contrasts. When using colours and patterns it is not recommended to combine red and green hues.

It focuses extensively on the issue of orientation of persons, which should be enhanced by the use of acoustic, material, light and colour contrasts. Suitable messages describing the place and character of the building must be located at the main entrances and detours. In very complicated buildings these facts should be conveyed by visual, acoustic and tactile information. To navigate persons with sensuous impairments it is required to use the so-called "two senses principle". The provision of information is described here in great detail. It is required that information is provided clearly (The clarity of information defines its legibility and easy comprehensibility.), concisely, accurately and timely. Text information is to be complemented with graphic symbols for increased comprehensibility by all persons. An important parameter is also the suitable height of the location of information and signs which is recommended at $1.200 \mathrm{~mm}$ to $1.600 \mathrm{~mm}$ above the walking surface. Their legibility, type and size, and surface reflectivity is also important. [3] Solution of the acoustic environment is also a detailed chapter, focusing on use by persons with a hearing impairment. The requirements for the acoustic environment are based mainly on the existence of various levels of hearing impairment and the thereto related use of compensation aids (amplification of sound, hearing aids and cochlear implants). All modifications should then be based on the fact that most persons with hearing impairments rely on eyesight for lip reading or watching facial gestures. Therefore, it is recommended to design suitable lighting, colours and visual contrasts in the environment.

\section{Conclusion}

Public areas (open spaces) form an integral part of urbanized areas which are freely accessible and where people can meet and spend time together. The quality of public areas, which people perceive during their use, is affected by several qualitative factors and one of them is the barrier-free aspect. Until now, the condition of public areas was evaluated mainly in terms of town attractiveness as a whole. For several years now the Czech Republic has belonged to a group of countries which have realized their responsibility for the elimination of barriers and is making efforts to remove barriers in public areas, not only in terms of urbanization and architecture but also sociologically. The issues of the life of persons with a health, mental or other handicap or limitation is not a marginal one; it affects a large number of persons and it is necessary to give it the appropriate attention. During the design or reconstruction of public areas one must make sure that their use is pleasant and intuitive, without complications, and easy for regular, as well as irregular users, with or without limitations. Security and smooth operation, together with the necessary spatial requirements specified by the respective legislation, must be provided for. A frequent insufficiency accompanying barrier free modifications is the absence of continuity and relations to the broader surroundings and routes. This is where disputable areas arise, where even through successful modifications (conforming to normative parameters) the main objectives of an accessible barrier - free environment are not fulfilled - mainly comprehensibility and safety. Therefore, it is clear that unless these areas are viewed comprehensively and as a whole, they will not be able to provide their users with the required comfort necessary for their correct use. The Czech legal environment accepts the requirements of CSN ISO 21542 which suitably complements current regulations - Regulation No. 398/2009 Coll., CSN 73 
4108 and others. However, one can see that in practice its requirements are neglected especially in the areas of contrasts, orientation and information systems, signs, acoustics (issues of persons with hearing impairments which are addressed very generally in Regulation No. 398/2009 Coll.) and general chapters defining the needs of individual users. Even through all the imperfections described in the text the issue of a barrier free (accessible) environment in the Czech Republic, compared to surrounding countries, is addressed comprehensively in legislation, as well as in the fields of education and practical application.

\section{Acknowledgment}

The work was supported from the funds of the Student Grant Competition of the VSB Technical University of Ostrava. Project registration number is SP2017/121.

\section{References}

[1] BILKOvA, A., KOCUROVA, P., NIEMIEC, B. and D. ORSAKOVA. The issue of barrier elimination in public spaces in the area of the OstravaSvinov transport hub. International journal of interdisciplinarity in theory and practice - ITPB. 2016, 2016(10), p. 113-116. ISSN 2344-2409.

[2] BILKOvA, A., KOCUROVA, P., NIEMIEC, B. and D. ORSAKOVA. The issue of barrier - free public places - the transport interchange OstravaSvinov. In: AL ALI, Mohamad a Peter PLATKO. Advances and Trends in Engineering Sciences and Technologies II. London: CRC Press, p. 729-734. ISBN 978-1-138-03224-8.

[3] Building construction - Accessibility and usability of the built enviroment. CSN ISO 21542 (73 4001). October 2013. Prague: Czech Standards Institute, 2013.

[4] Decree No 398/2009. Sb, on general technical requirements ensuring the barrier - free use of buildings. In: The Collection of Laws. 5 November 2009. ISSN 1211-1244. As amended.

[5] MEDKOVA, P. Manual for Creation of Public Areas of the Capital Prague. ed., 2014. Prague: IPR Praha. ISBN 978-80-87931-11-0.

[6] MEDKOVA, P. Prague Public Space Development STRATEGY / Proposal. ed., 2016. Prague: IPR Praha. ISBN 978-80-87931-49-3.

[7] Moravian-Silesian Plan to Equalize Opportunities for Citizens with Disabilities for 2014-2020. Os- trava: Moravian-Silesian Region, 2014, 46 p. ISBN 978-80-87503-51-5. 